\title{
A portable device based on the interrupter technique to measure bronchodilator response in schoolchildren
}

\author{
P.D. Bridge, H. Lee, M. Silverman
}

\begin{abstract}
A portable device based on the interrupter technique to measure bronchodilator response in schoolchildren. P.D. Bridge, H. Lee, M. Silverman. (CERS Journals Ltd 1996.

ABSTRACT: A new device for measuring airway resistance following brief airflow interruption (Microlab 4000; Micromedical Ltd, UK) was evaluated in 25 asthmatic school children in comparison with well-established methods.

Airway resistance was measured during brief airflow interruption (Rint), before and after administration of salbutamol $200 \mathrm{\mu g}$ by metered-dose inhaler, and in the spirometric parameters, forced expiratory volume in one second (FEV1) and peak expiratory flow (PEF), and total respiratory system resistance at $6 \mathrm{~Hz}(\mathrm{Rrs}, 6)$ measured by the forced oscillation technique (FOT). The sensitivity index (SI) (mean change/baseline standard deviation) was calculated for each subject.

At baseline, interrupter conductance, the reciprocal of $R$ int, correlated well with FEV1 $(r=0.837 ; p<0.001)$ and PEF $(r=0.773 ; p<0.001)$, and $R$ int correlated highly with $R r s, 6(r=0.942 ; p<0.001)$. The median intrasubject coefficient of variation of the interrupter method was higher than the FOT or either spirometric parameter: $R$ int $11 \%$, Rrs, $6 \%$, FEV1 5\% and PEF 5\%. However, the sensitivity to detect change after bronchodilator, expressed as the median SI, did not differ significantly between measurements: $R$ int 3.5, Rrs,6 3.6, FEV1 2.4 and PEF 3.0. A significant response (SI >2) was shown by the interrupter in 22 of the subjects compared with 16 by FEV1.

The interrupter technique is useful for assessing changes in airway calibre in asthmatic school children, with a sensitivity at least as good as standard methods. Such a device could be of particular value in those too young to perform spirometry.

Eur Respir J., 1996, 9, 1368-1373.
\end{abstract}

Dept of Paediatrics and Neonatal Medicine, Royal Postgraduate Medical School, Hammersmith Hospital, London, UK.

Correspondence: M. Silverman

Dept of Child Health

Clinical Sciences Building

Leicester Royal Infirmary

P.O. Box 65

Leicester LE2 7LX

UK

Keywords: Airway resistance bronchodilator therapy

interrupter method

Received: May 291995

Accepted after revision March 191996
An acute response to the administration of a bronchodilator, one of the diagnostic criteria of asthma, can only be quantified by lung function measurement. This does not present a problem in school-age children and adults or even in sedated infants. However, there remains a gap in our knowledge of the airway response to bronchodilating agents in toddlers and preschool children because of the lack of available lung function tests.

Peak flow meters and spirometers are reported to be usable by a small proportion of children as young as 3-5 yrs [1-3], although in our experience preschool children cannot be relied upon to do this consistently or speedily. Blowing sharply enough, blowing for at least $1 \mathrm{~s}$ and continuing to expire down to residual volume prove to be major hurdles. The measurement of respiratory system resistance by the forced oscillation technique (FOT) has been recommended for children as young as $2.5 \mathrm{yrs}$ [4], but has not been fully assessed for use with exclusively preschool children. We and others have reported difficulty in obtaining consistent measurements using the FOT in young children in response to bronchoconstricting agents [5-9]. The reasons include: the need to breathe against the oscillating column of air; the mandatory length of quiet, consistent breathing required to obtain a measurement (up to $16 \mathrm{~s}$ ); and the importance of maintaining a consistently patent upper airway.

Although change in transcutaneous oxygen tension $\left(P \mathrm{tc}, \mathrm{O}_{2}\right)$ (a very indirect index of airway function, probably the result of a ventilation-perfusion inequality) has been shown to be a reliable measurement to assess response to bronchoconstricting agents in preschool children $[10,11]$, it is unlikely to be of value in the measurement of bronchodilation because of the transient hypoxaemia which occurs after the administration of a bronchodilator [12].

The interrupter technique, a noninvasive method of measuring airway resistance, was first described in 1927 [13], but has never been widely accepted as a clinical tool. It is based on the assumption that during an imperceptibly brief interruption of airflow during tidal breathing, the pressure changes at the airway opening can be used to determine the alveolar pressure at the moment of interruption and, hence, knowing the flow immediately prior to interruption, resistance can be calculated. Reasons for the reluctance to use the technique include: the lack of standardization of a method for calculating the driving pressure from the mouth pressure signal and the absence of any reference values. It is noninvasive, 
requires minimum patient co-operation and its brevity and the absence of an oscillating column of air suggests that it may be generally better tolerated by young patients than the FOT. Responses such as glottic narrowing are unlikely to occur, because measurements are virtually imperceptible and are made during quiet breathing

Recently, the physiological basis and clinical utility of the interrupter technique has been re-evaluated, with some promising results [14-16], and theoretical analysis by BATES et al. [17] has validated the technique. Although upper airway compliance may lead to an underestimation of airway resistance [18], this can be minimized by supporting the cheeks and floor of the mouth. It has been shown that the interrupter technique can be successfully applied to healthy adults in order to provide an index of change in airway calibre following bronchoconstriction [19]. Others have demonstrated its value following the administration of bronchodilators in the presence of preexisting airflow obstruction [20,21]. These studies have all been performed in laboratory settings.

The object of this study was to evaluate the commercially available interrupter device, the Microlab 4000, in assessing the response to bronchodilator therapy in schoolchildren, with a view to its introduction into the preschool age group. We wished to determine the relative sensitivity of the technique compared with other standard techniques in the clinically relevant setting of a children's out-patient clinic. Because we aimed to compare devices in clinical use, healthy control subjects were not measured.

\section{Methods}

\section{Subjects}

The 25 asthmatic children included in this study were aged 5-15 (median 8) yrs (14 boys and 11 girls), and had values of forced expiratory volume in one second (FEV1) ranging $54-111 \%$ of predicted [22]. The children were either out-patients with clinical symptoms or in-patients with acute severe asthma, in all of whom a bronchodilator response was routinely measured as part of their clinical assessment. Patients were not included if they had taken bronchodilator therapy within $4 \mathrm{~h}$ of the tests. With the agreement of their parents, the children were asked if they were willing to perform the extra breathing tests.

\section{Protocol}

The subjects performed several baseline measurements on each of three devices in the order: interrupter, forced oscillation and spirometry. On each device, one or two practice attempts were made before starting to record the data. Salbutamol $(200 \mu \mathrm{g})$ was administered from a metered-dose inhaler and Volumatic ${ }^{\circledR}$ spacer (Glaxo Wellcome UK). After $15 \mathrm{~min}$, the measurements were repeated in the same order. On two separate visits, 10 patients had measurements using the interrupter device after both salbutamol and placebo (two puffs) given in a random order, single-blind to the patient. The tests took less than 5, 7 and $5 \mathrm{~min}$, for the interrupter, FOT and spirometry, respectively, such that the total time to perform all three sets of tests was invariably less than 20 min. The same person performed the tests on all of the patients and a trained asthma nurse supervised the administration both of placebo and bronchodilator therapy throughout the study. Those performing the placebo tests were given the placebo whilst the asthma nurse was assessing their inhaler technique.

\section{Interrupter technique}

Interrupter resistance was measured using a single commercial device (Microlab 4000; Micromedical Ltd, Rochester, UK) throughout the tests. After a period of quiet breathing, a single, $100 \mathrm{~ms}$, shutter closure occurred automatically in response to a trigger, during inspiration, at a flow of $80 \%$ of the previous tidal peak flow. It was not possible to set the flow at which occlusion occurred. Subjects were unable to anticipate the trigger event but were able to hear the valve closing. Subjects were placed in an identical, comfortable posture. They breathed quietly through a cardboard mouthpiece $(2.7 \mathrm{~cm}$ diameter or, in the-case of younger children, $2.0 \mathrm{~cm}$ diameter) with the nose clipped, the cheeks and pharynx supported and the neck slightly extended [5]. Attempts were not accepted if the patient was observed to be breathing irregularly, or if the mouth pressure-time curve $(P \operatorname{mo}(\mathrm{t}))$ was not of a consistent shape, as described in the literature $[5,23,24]$.

The method of analysis involved the determination of the pressure from a linear back-extrapolation of the mean of two $10 \mathrm{~ms}$ sections of the postinterruption signal (centred on 30 and $70 \mathrm{~ms}$ ) to an arbitrary time $(15 \mathrm{~ms}$ ) after the onset of airway occlusion to calculate $R$ int $[5$, 20]. This method gave the lowest baseline variability and the highest sensitivity index (SI), during bronchoconstrictor challenge in children [5]. The ratio of this pressure to the flow immediately prior to interruption was used to derive interrupter resistance. For statistical purposes, the value of the measurement was recorded as the mean of six accepted measurements, the subject coming off the mouthpiece for at least five breaths between each attempt. Subjects were excluded if less than six acceptable attempts were obtained, either before or after bronchodilator administration.

\section{Forced oscillation technique}

Total respiratory system resistance was determined by the FOT, as described by LANDSER et al. [25] and ourselves [7]. The computer indicated the coherence value, a measure of the signal-to-noise ratio, thus allowing the operator to reject a particular measurement if the coherence was less than $95 \%$. For this test, subjects breathed via the wide bore mouthpiece $(2.7 \mathrm{~cm})$. For statistical purposes, the value of the measurement was recorded as the mean of six accepted measurements, the subject coming off the mouthpiece for at least five breaths between each attempt. Subjects were excluded if less than six acceptable attempts were obtained, either before or after bronchodilator administration. 


\section{Spirometry}

Spirometric measurements were made on an electronic spirometer based on a pneumonotachograph (Vitalograph Compact; Vitalograph, Buckingham UK). The patients performed this test whilst standing, using identical mouthpieces to those used for the interrupter measurements. Each subject performed three acceptable blows and all forced vital capacity (FVC), FEV1 and peak expiratory flow (PEF) values were recorded. Since all our subjects were familiar with the FVC manoeuvre and, furthermore, we wished to avoid errors caused by changes in bronchomotor tone, the subjects were asked to perform only three blows which satisfied the following criteria: 1) an observable full inspiration; 2) lips sealed around the mouthpiece; and 3) a forced expiration showing a distinct peak. For statistical purposes, the value of the measurement recorded was the mean of three successful attempts.

\section{Calibration}

Each of the devices was calibrated according to the manufacturer's instructions. The spirometer was calibrated at the start of each day using a $1 \mathrm{~L}$ precision syringe (Vitalograph, UK) in multiples up to $4 \mathrm{~L}$. The interrupter was precalibrated for pressure by the manufacturers. Volume and flow, its time integral, were calibrated before each patient using a precision syringe (Vitalograph, UK). The FOT equipment was calibrated at the start of each session using a reference linear resistance, which ensures that the response both of the transducers and the attached tubing was calibrated up to $48 \mathrm{~Hz}$.

\section{Expression of results and statistical analysis}

Baseline repeatability was assessed using the withinsubject coefficient of variation $(\mathrm{CoV})$, the standard deviation of repeat measurements expressed as a percentage of the mean. Linear regression analysis was used to determine the relationship, under baseline conditions, between interrupter measurements, FOT measurements and spirometry. The SI was calculated in a standard manner for each individual as the mean absolute change in lung function divided by the standard deviation of baseline measurements. This was always given a positive value. The values of the different measurements were expressed using the median (range) to allow for the nonparametric distribution of the data. Freidman's test was used to compare sensitivity indices between all four different parameters, and Wilcoxon's test was used to further investigate individual differences between the interrupter and the other measurements. In all cases, a p-value of less than 0.05 was considered to be statistically significant.

\section{Results}

\section{Baseline values}

Interrupter conductance ( $G$ int) correlated well with FEV1 ( $\mathrm{r}=0.837$; $\mathrm{p}<0.001$ ) (fig. 1) and PEF ( $\mathrm{r}=0.773$;

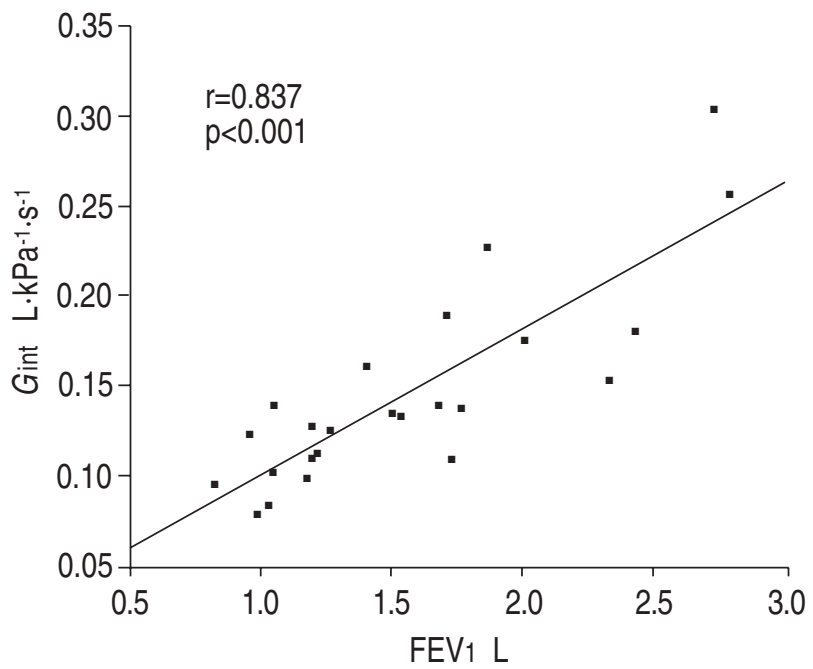

Fig. 1. - Correlation between forced expiratory volume in one second $\left(\mathrm{FEV}_{1}\right)$ and interrupter conductance $(G$ int $)$ at baseline, showing calculated regression line.

$\mathrm{p}<0.001)$. Interrupter resistance (Rint) correlated highly with total respiratory system resistance at $6 \mathrm{~Hz}(R \mathrm{rs}, 6)$ $(\mathrm{r}=0.942 ; \mathrm{p}<0.001)$ with no systematic bias (fig. 2$)$. The repeatability of the interrupter method as measured by the median (range) intrasubject coefficient of variation $(\mathrm{CoV})$, was significantly less than for either spirometric parameter (table 1). On average, $91 \%$ of individual measurements were accepted on the interrupter compared with $83 \%$ for the FOT and $77 \%$ by spirometry.

Of the 10 patients who took the placebo, there was no significant change in interrupter resistance values after placebo (median values before $0.69 \mathrm{kPa} \cdot \mathrm{L}^{-1} \cdot \mathrm{s}$; and after $\left.0.70 \mathrm{kPa} \cdot \mathrm{L}^{-1} \cdot \mathrm{s} ; \mathrm{p}=0.47\right)$. The standard deviation of the difference between pre- and post-placebo values was 0.04 $\mathrm{kPa} \cdot \mathrm{L}^{-1} \cdot \mathrm{s}$. In no subject was the change statistically significant.

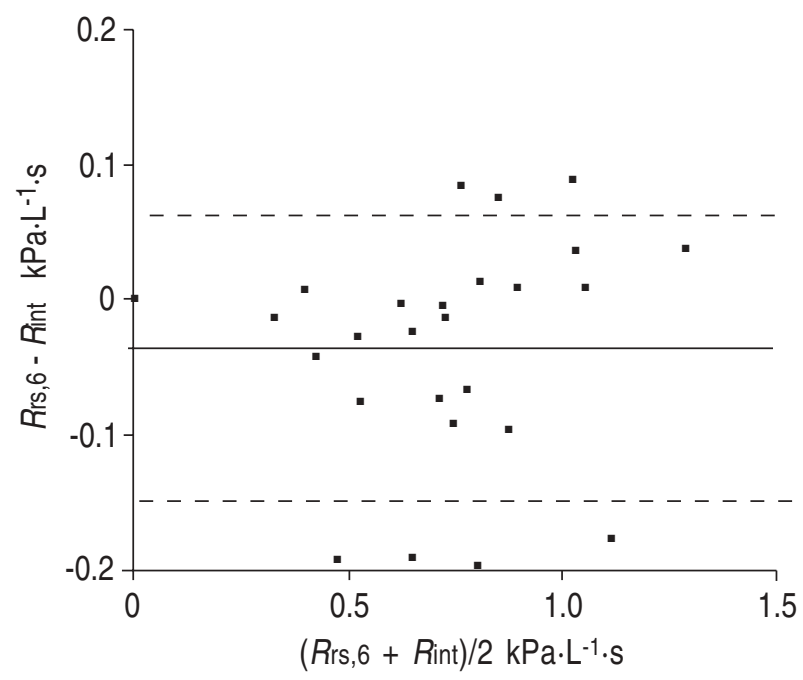

Fig. 2. - Altman-Bland plot of mean baseline resistance values for the forced oscillation and interrupter techniques $\left(\left(R_{\mathrm{rs}, 6}+R_{\text {int }}\right) / 2\right) \mathrm{com}-$ pared with their differences (Rrs,6 - Rint). Showing mean difference (solid line) and 95\% confidence limits (dotted lines). There was no systematic difference between the methods. Rrs,6: total respiratory resistance by forced oscillation technique at $6 \mathrm{~Hz}$; Rint: resistance by interrupter technique. 
Table 1. - Results for all 25 subjects

\begin{tabular}{|c|c|c|c|c|c|}
\hline & & Rint & $R \mathrm{rs}, 6$ & FEV1 & $\mathrm{PEF}$ \\
\hline $\begin{array}{l}\text { Intrasubject } \mathrm{CoV} \text { under baseline } \\
\text { conditions \% }\end{array}$ & 11 & $(4-18)$ & $9 \quad(4-18)$ & $5 \quad(1-11)$ & $5 \quad(1-12)$ \\
\hline Sensitivity index & 3.5 & $(1.1-8.6)$ & $3.6(1.0-8.0)$ & $(0-16.5)$ & $3.0(1.2-12.7)$ \\
\hline Subjects with SI $>2 n$ & 22 & & 21 & 16 & 21 \\
\hline Change after salbutamol ${ }^{\dagger} \%$ & -36 & $(-15--55)$ & $-35 \quad(-8--50)$ & $+12(-2-44)$ & $(6-49)$ \\
\hline
\end{tabular}

Values are presented as median, and range in parenthesis. CoV: coefficient of variation; Rint: resistance by interrupter technique; $R \mathrm{rs}, 6$ : total respiratory resistance by forced oscillation technique at $6 \mathrm{~Hz}$; FEV1: forced expiratory volume in one second; PEF: peak expiratory flow; SI: sensitivity index (mean absolute change in lung function divided by baseline standard deviation). $\uparrow$ : change expressed in percentage of baseline value.

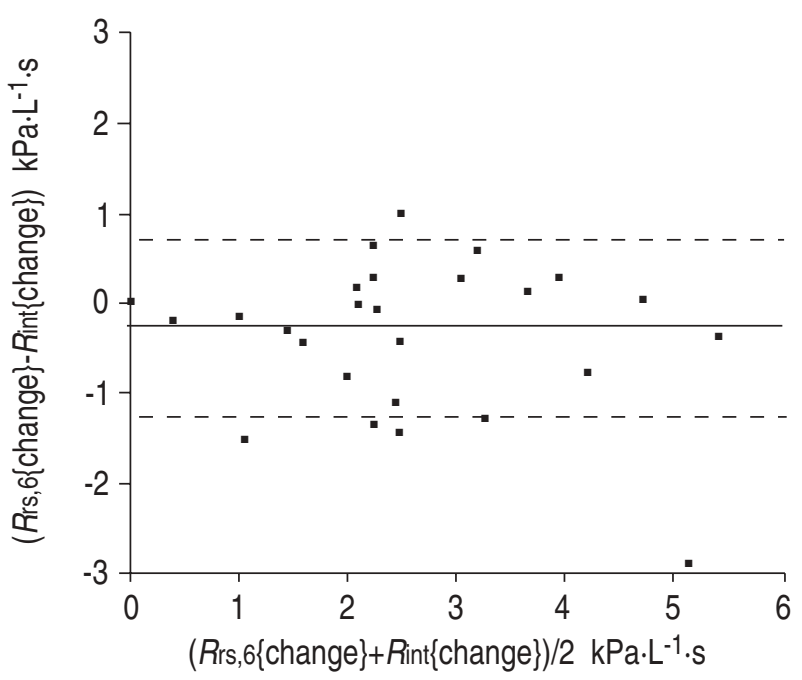

Fig. 3. - Altman-Bland plot of the mean change in resistance after bronchodilator $((R \mathrm{rs}, 6$ change $\}+R$ int $\{$ change $\}) / 2)$ compared with the differences $(R \mathrm{rs}, 6$ \{change $\}$ - Rint $\{$ change $\})$ in the mean change, showing mean difference (solid line) and 95\% confidence limits (dotted lines). There was no systemic difference between the methods.

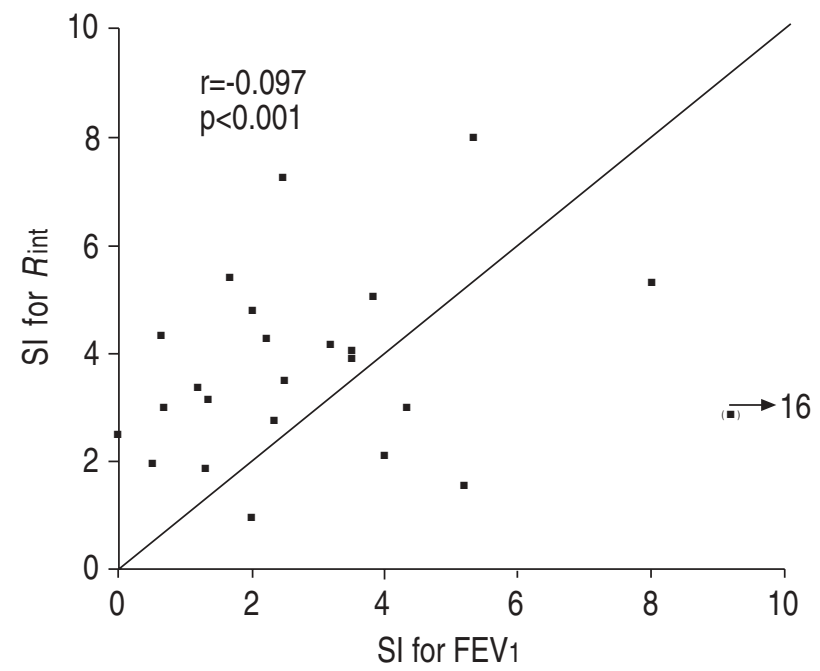

Fig. 4. - Comparison of sensitivity indices (SI) for forced expiratory volume in one second (FEV1) and interrupter resistance ( $R$ int). There was a very poor correlation between the two but for most individuals $R$ int was more sensitive than FEV1. Line of identity shown. The individual data point in brackets had SI (FEV1) of 16. Sensitivity index; mean absolute change in lung function divided by baseline standard deviation.

\section{Changes after bronchodilator}

Resistance values as measured by the interrupter and FOT decreased after bronchodilator in all subjects by a median of 36 and $35 \%$, respectively (table 1 ). The changes in resistance were similar for the two methods, with no systematic bias (fig. 3). For most of the subjects, both the FEV1 and PEF increased (by a median of 12 and $14 \%$, respectively) (table 1), although some changes were very small and in one subject the FEV1 was slightly less after bronchodilator. The median SI for the interrupter technique was not significantly different from any of the other measurements. However, comparing the interrupter resistance with FEV1, the difference approached statistical significance. The correlation between the SI for FEV1 and Rint was very poor (fig. 4). The scatter for PEF was also very wide. The sensitivities of $R$ int and Rrs,6 were similar with no systematic bias.

\section{Discussion}

Our aim was to study a commercially available interrupter device to measure change in airway resistance following bronchodilator therapy in schoolchildren. The device was compared with the FOT, which also required relatively little co-operation, and spirometry, which required more understanding and co-operation but which has been the gold standard for many years. Ideally, we would have liked to use younger subjects because preschool children are most likely to benefit from the interrupter technique since they are too young to co-operate with conventional tests.

The device used, the Microlab 4000, is capable of triggering during either inspiration or expiration and either discretely (i.e. on an individual breath basis) or repetitively, whilst the subject breathes through it continuously until sufficient measurements have been recorded. In our study, the measurements were all taken during inspiration to avoid any problems associated with dynamic changes in airway resistance during expiration. A separate study of 22 asthmatic children showed no significant difference between measurements taken during continuous breathing and those taken discretely, suggesting that, in practice, it may be possible to select the mode to suit the individual patient. After a period of quiet breathing, the interrupter method used in our study triggers at $80 \%$ of the previous tidal peak flow, whereas others $[5,19,20]$ have used devices set to trigger a 
specific flow. This could be important, since resistance is flow- and volume-dependent. If the tidal flow pattern changes after an intervention, such as the administration of bronchodilator, then the interruption will occur at a different lung volume, with potential bias to the resultant resistance value. One recent study failed to show any differences in interrupter resistance in children, when performing occlusions at different lung volumes [26]. Also, preliminary results from our current study using the same device, failed to show any correlation between flow and interrupter resistance, over the range of flow encountered during 20 repeat measurements of $R$ int in each of 10 children.

For the FOT, each measurement of $R$ rs, 6 was the timeweighted average during all phases of breathing over a recording period of $16 \mathrm{~s}$. Due to the frequency dependence of resistance, in children with asthma, the greatest change in $R$ rs, 6 is found at the lower frequencies, hence, the values used in this study were obtained at a frequency of $6 \mathrm{~Hz}$, the lowest frequency with a coherence function of $>0.95$ in all subjects before and after bronchodilator. It should be noted that Rrs,6 was averaged over the whole respiratory cycle and over many breaths, whereas, Rint measured inspiratory resistance during single breaths. Theoretically, the two techniques are affected by the same factors, such as varying lung volume and upper airway compliance, and this is reflected by the lack of systematic bias between the two measurements (fig. 2) [27].

Even though interrupter resistance correlated significantly with PEF and FEV1 our data showed a large scatter of sensitivity indices (fig. 4). This discrepancy may relate to the differences between subjects in the effects of topical $\beta_{2}$-agonists on airway smooth muscle, or might simply be due to differences in their the site of action in the airway, since $R$ int is likely to be dominated by large airway function whereas FEV1 is affected by more peripheral airway calibre. The mechanism of action could differ between subjects, for instance in the effect of the "big breath" manoeuvre. Because the FVC manoeuvre can cause a change in bronchomotor tone [28], this measurement was always the last to be attempted by each patient.

To our knowledge, there is no evidence that quiet breathing tests alter bronchial tone and, hence, are likely to result in a bias towards subsequent tests. The interval between the first interrupter measurement and the last vital capacity manoeuvre was short and, given that the maximum effect of salbutamol is likely to occur about 20 min after inhalation, it is likely, if anything, that $R$ int would have underestimated rather than overestimated the change in true resistance. Further exploration of the difference between Rint and FEV1 in the detection of response to bronchodilating agents might be profitable.

Normally, with spirometry, the best blow is accepted according to American Thoracic Society guidelines [29] but, for statistical purposes, we used data from all three blows. With the interrupter and forced oscillations, a preliminary statistical study showed that six measurements were needed from which to obtain a reliable mean value. Although this may have a small effect on the statistics and, in particular, the SI, it was felt that the fact that the devices were being used in a manner reflecting their routine clinical use justified our decision to require only three blows on the spirometer but six both on the interrupter and the FOT. With this age group, the median baseline $\mathrm{CoV}$ of the interrupter was significantly higher than that for either FEV1 or PEF (table 1), but the relatively large changes after salbutamol resulted in comparable values for median SI (table 1), the important criterion of the ability to detect change within individual subjects. The results of this study do not support the use or safety of this device or technique in tests designed to assess the response to bronchoconstricting agents.

In conclusion, the interrupter technique was well-tolerated and simple to perform, requiring only a portable and relatively inexpensive device and less patient cooperation than the more complex forced oscillation technique. Our results show that this particular commercial version of the interrupter technique can be used to detect a response to bronchodilator therapy, with comparable sensitivity to the forced oscillation method and spirometry in schoolchildren. The option to preset the flow at which the measurement is made might enhance its accuracy. However, before the interrupter technique becomes a part of standard lung function equipment, more work is needed to determine reference values and the best configuration (inspiration or expiration, discrete or continuous mode). Based on our experience with schoolchildren, it should be a suitable device for assessing bronchodilator therapy in younger children who have the ability to breathe quietly through a mouthpiece or a paediatric face mask.

Acknowledgements: The authors are grateful to Micromedical for the loan of the interrupter device. PB was supported by a grant from the U.K. National Asthma Campaign.

\section{References}

1. Kanengeiser S, Dozor AJ, Forced expiratory manoeuvres in children aged 3 to 5 years. Pediatr Pulmonol 1994; 18: 144-149.

2. Turner DJ, Landau LI, LeSouëf PN. The effect of age on bronchodilator responsiveness. Pediatr Pulmonol 1993; 15: 98-104.

3. LeSouëf PN, Lafortune BC, Landau LI. Spirometric assessment of asthmatic children aged 2 to 6 years (abstract). Aust NZ Med J 1986; 16: 625.

4. Duiverman EJ, Neijens HJ, van Stick R, et al. Bronchial responsiveness in asthmatic children aged 3 to 8 measured by forced pseudorandom noise oscillation. Bull Eur Physiopathol Respir 1986; 22: 27-34.

5. Phagoo SB, Wilson NW, Silverman M. Evaluation of the interrupter technique for measuring airway resistance in 5 year old asthmatic children. Pediatr Pulmonol 1996; 20: 387-395.

6. Wilson NW, Bridge PD, Silverman M. Bronchial responsiveness and symptoms in 5-6 year old children: a comparison of direct and indirect challenge. Thorax 1995; 50: 339-345.

7. Wilson NW, Bridge PD, Phagoo SB, Silverman M. The measurement of methacholine responsiveness in 5 year old children: three methods compared. Eur Respir $J$ 1995; 8: 364-370.

8. König P, Hordvik N, Pimmel R. Forced random noise resistance determination in childhood asthma. Chest 1984; 86: 884-890. 
9. Nussbaum E, Galant SP. Measurement of total respiratory resistance in children by a modified forced oscillation method. Pediatr Res 1984; 18: 139-145.

10. Wilson NM, Phagoo SB, Silverman M. Atopy, bronchial responsiveness and symptoms in wheezing 3 year olds. Arch Dis Child 1992; 67; 491-495.

11. Mochizuki H, Mitsuhasi M, Tokayama K, et al. A new method of estimating bronchial hyperresponsiveness in younger children. Ann Allergy 1985; 55: 162-166.

12. Connett G, Lenney W. Prolonged hypoxaemia after nebulised salbutamol. Thorax 1993; 48; 574-575.

13. Von Neergaard K, Wirz K. Die Meeund der Strömungswiederstande in den Atemwegen des Meschen insbesondere bei Asthma und Emphysema. Z Klin Med 1927; 105: 51-82.

14. Jackson AC, Milhorn HT, Norman JR. A re-evaluation of the interrupter technique for airway resistance measurement. J Appl Physiol 1974; 36: 264-268.

15. Listro G, Stänescu D, Rodenstein D, Veriter C. Reassessment of the interrupter technique for measuring flow resistance in humans. J Appl Physiol 1989; 67: 933-937.

16. Clarke J, Jaeger MJ, Zumrick J, et al. Respiratory resistance from 1 to 46 ATA measured with the interrupter technique. J Appl Physiol:Respirat Environ Exercise Physiol 1982; 52: 549-555.

17. Bates JHT, Abe T, Romero P, Sato J. Measurement of alveolar pressure in closed-chest dogs during flow interruption. J Appl Physiol 1989; 76: 488-492.

18. Bates JHT, Sly PD, Kochli T, Martin JG. The effect of a proximal compliance on interrupter measurements of resistance. Respir Physiol 1987; 70: 301-312.

19. Phagoo SB, Watson RA, Pride NB, Silverman M. Accuracy and sensitivity of the interrupter technique for mea- suring the response to bronchial challenge. Eur Respir J 1993; 6: 996-1003.

20. Chowienczyk PJ, Lawson CP, Lane S, et al. A flow interruption device for measurement of airway resistance. Eur Respir J 1991; 4: 623-628.

21. Lulling J, Delwiche JP, Prignot J. Evaluation of the onset of bronchodilating effect by interruption of the airflow method. Eur J Respir Dis 1980; 61: 108-112.

22. Polgar G, Promadhat V. Pulmonary function testing in children: techniques and standards. Philadelphia, Saunders, 1971.

23. Vuilleumier P. Uber eine methode zur messung des intraalveolaren drokes und der stromungswiderstande in den atemwegen des menschen. Z Klin Med 1944; 143: 698-717.

24. Mead J, Whittenberg JL. Evaluation of airway interruption as a method for measuring airflow resistance. $J$ Appl Physiol 1954; 6: 408-416.

25. Lándsèr FJ, Nagels J, Demedts K, et al. A new method to determine frequency characteristics of the respiratory system. J Appl Physiol 1976; 4: 101-106.

26. Llerena-Bongeot $\mathrm{C}$, Oswald-Mammosser L, Donato $\mathrm{F}$, et al. Measurement of airway resistance by a flow interruption method (Rint) in children. Eur Respir J 1993; 6: A139s.

27. Carter ER, Stecenko AA, Pollock BH, Jaeger ML. Evaluation of the interrupter technique for the use of assessing airway obstruction in children. Pediatr Pulmonol 1994; 17: 211-212.

28. Orehek J, Gaynard P, Grimaud C, Charpin J. Effect of maximal respiratory manoeuvres on bronchial sensitivity of asthmatic patients as compared to normal people. $B M J$ 1975; $1: 123-125$.

29. American Thoracic Society. Standardisation of spirometry. Am Rev Respir Dis 1987; 136: 285-1298. 